\title{
Disruption of the oxidative Pentose Phosphate Pathway stimulates high-yield production using resting Corynebacterium glutamicum in the absence of external electron acceptors
}

Shen, Jing; Chen, Jun; Solem, Christian; Jensen, Peter Ruhdal; Liu, Jianming

Published in:

Applied and Environmental Microbiology

Link to article, DOI:

10.1128/AEM.02114-20

Publication date:

2020

Document Version

Peer reviewed version

Link back to DTU Orbit

Citation (APA):

Shen, J., Chen, J., Solem, C., Jensen, P. R., \& Liu, J. (2020). Disruption of the oxidative Pentose Phosphate Pathway stimulates high-yield production using resting Corynebacterium glutamicum in the absence of external electron acceptors. Applied and Environmental Microbiology, 86(24), [e02114-20].

https://doi.org/10.1128/AEM.02114-20

\section{General rights}

Copyright and moral rights for the publications made accessible in the public portal are retained by the authors and/or other copyright owners and it is a condition of accessing publications that users recognise and abide by the legal requirements associated with these rights.

- Users may download and print one copy of any publication from the public portal for the purpose of private study or research.

- You may not further distribute the material or use it for any profit-making activity or commercial gain

- You may freely distribute the URL identifying the publication in the public portal 
1 Disruption of the oxidative Pentose Phosphate Pathway stimulates high-yield production using resting Corynebacterium glutamicum in the absence of external electron acceptors

3 Jing Shen ${ }^{\text {a }}$, Jun Chen ${ }^{a}$, Christian Solem ${ }^{\text {a }}$, Peter Ruhdal Jensen ${ }^{a^{*}}$, Jian-Ming Liu ${ }^{{ }^{*}}$

$4 \quad{ }^{a}$ The National Food Institute, Technical University of Denmark, Kongens Lyngby 2800, Denmark

$6 \quad *$ Corresponding author:

7 Jian-Ming Liu

8 National Food Institute, Technical University of Denmark, DK-2800 Kgs. Lyngby, Denmark;

9 telephone: +45 91922228; fax: +45 45932809; e-mail: jial@dtu.dk

Peter Ruhdal Jensen 


\section{Abstract}

Identifying and overcoming the limitations preventing efficient high-yield production of chemicals remain to be an important task in metabolic engineering. In an attempt to rewire Corynebacterium glutamicum into producing ethanol, we attained a low yield (63\% of the theoretical), when using resting cells on glucose, and large amounts of succinate and acetate were formed. To prevent the by-products formation, we knocked out the malate dehydrogenase and replaced the native E3 subunit of the pyruvate dehydrogenase complex (PDHc) with the one from Escherichia coli, which is only active under aerobic conditions. However, this tampering resulted in a 10 times reduced glycolytic flux as well as a greatly increased NADH/NAD ${ }^{+}$ratio. By substituting glucose with fructose, we found that the glycolytic flux was greatly enhanced, which led us to speculate whether the source of reducing power could be the the pentose phosphate pathway (PPP) that is bypassed when fructose is metabolized. Indeed, after shutting down the PPP by deleting the $z w f$ gene, encoding glucose-6-phosphate dehydrogenase, the ethanol yield on glucose increased significantly to $92 \%$ of the theoretical. Based on that, we managed to re-channel the metabolism of $C$.

\section{Importance}

The widely used industrial workhorse $C$. glutamicum possesses a complex anaerobic metabolism under non-growing conditions and we demonstrate here that the PPP in resting C. glutamicum is a source of reducing power that can interfere with otherwise redox balanced metabolic pathways and 
reduce yields of desired products. By harnessing this physiological insight, we employed the PPPinactivated platform strains to produce ethanol, D-lactate and alanine using the dairy waste - whey permeate as the feedstock. The production yield is high and our results show that inactivation of the PPP flux in resting cells is a promising strategy when the aim is to use non-growing C. glutamicum cells for producing valuable compounds. Overall, we described the benefits to disrupt the oxidative PPP in non-growing C. glutamicum and provide a feasible approach towards waste valorization.

\section{Introduction}

51 Corynebacterium glutamicum is widely employed for large-scale fermentative production of amino

52 acids, especially L-glutamate and L-lysine (1). In recent years, the fast development of tools for

53 genetic engineering as well as for studying the systems biology of C. glutamicum has accelerated

54 research on its metabolism and regulatory network (2-4). It is now apparent, that $C$. glutamicum has

55 a great potential for industrial production of a wide range of useful compounds, e.g. organic acids

56 and biofuels $(5,6)$. Whereas amino acids normally are produced under highly aerated conditions,

57 organic acids are generated under anaerobic conditions $(7,8)$. When oxygen and external electron

58 acceptors are absent, C. glutamicum displays limited growth in a medium devoid of rich

59 components, but retains an active fermentative metabolism. Glucose, for instance, is metabolized

60 via glycolysis to pyruvate that can be reduced into lactate. If carbon dioxide is available, anaplerotic

61 reactions can lead to formation of oxaloacetate, which normally is reduced into succinate $(7,9)$.

62 Sodium bicarbonate, as a source of carbon dioxide, was found to stimulate the formation of

63 succinate as well as the glycolytic flux $(7,10)$, and blocking the formation of either of these

64 compounds was found to hamper glycolysis. In one study, the NADH-sensitive glyceraldehyde-3-

65 phosphate dehydrogenase (GAPDH) was overexpressed, which improved the glucose consumption 
rate (11), and it appears that the anaerobic glycolytic flux in $C$. glutamicum is sensitive to the

$67 \mathrm{NADH} / \mathrm{NAD}^{+}$ratio (9). Thus, when engineering $C$. glutamicum for the purpose of bio-production under anaerobic conditions, it is imperative that the redox balance is considered carefully.

It has previously been reported that $C$. glutamicum can be engineered into producing ethanol under anaerobic conditions by heterologous expression of the pyruvate decarboxylase (PDC) and the alcohol dehydrogenase (ADHB) from Zymomonas mobilis (12-14). However, a low yield production was achieved due to formation of by-products such as lactate, succinate and acetate (12). Lactate production could be eliminated by disrupting the lactate dehydrogenase gene (ldhA), and this resulted in a 3-fold higher ethanol yield compared to the wild-type strain expressing PDC and ethanol.

In this study, we observed low yield production of ethanol from glucose under anoxic conditions in ADHB (12). By further deleting the $p p c$ gene, encoding PEP carboxylase, succinate formation was reduced, but controlling the $\mathrm{pH}$ was still found to be necessary $(12,14)$. In principle, ethanol formation is balanced redox-wise, as all the NADH generated in glycolysis is re-oxidized when 2 moles of ethanol are formed from 1 mole of glucose, and it is reasonable to expect that simultaneous blocking of lactate and succinate formation should lead to a high-yield production of the absence of an external electron acceptor. Characterization of strains blocked in NADH consuming and forming steps prompted us to investigate if the PPP could be a source of reducing power. We found this to be the case and based on our findings, we managed to divert most of the carbon flux (glucose) towards either ethanol or D-lactate by inactivating the PPP. Furthermore, the PPP disrupted platform strains were employed for high-yield production of ethanol, D-lactate and alanine from lactose contained in dairy waste streams, which provided excellent examples of turning waste into value. 
Results

Deletion of the $m d h$ gene represses glucose consumption by resting cells.

91

92

We have previously rewired $C$. glutamicum strain into producing ethanol. The rewired strain, JS122 (15), expresses pyruvate decarboxylase and alcohol dehydrogenase from Z. mobilis, and lacks lactate dehydrogenase and phosphoenolpyruvate (PEP) carboxylase activities (Fig. 1). When use glucose as the carbon source for JS122, the yield for ethanol production only reached $63 \%$ of the theoretical maximum, where considerable amounts of succinate and acetate were formed. In principle it is redox-neutral for ethanol production and could lead to a much higher yield. In order to increase the production yield of ethanol and elucidate the limitations in the anaerobic metabolism of C. glutamicum, we decided to further investigate the anaerobic metabolic flux and its controlling factors.

Since the method we applied for producing ethanol depends on non-growing cells and a high cell density is required to achieve a good productivity, it is imperative that the cells can readily be amplified aerobically to high cell densities on cheap mineral medium. Thus, the strain needs functional anaplerotic pathways to replenish oxaloacetate, and it has previously been found that either pyruvate carboxylase (PYC) or PEP carboxylase (PEPC) activity is needed (16). Thus, inactivating both of these enzymes is not a viable solution for increasing ethanol yield. In an attempt to reduce the formation of succinate, we inactivated the $m d h$ gene encoding malate dehydrogenase, resulting in strain JS124. JS124 generated 5-fold less succinate, and its ethanol yield increased to $71.5 \%$ of the theoretical maximum. Unexpectedly, the glucose consumption rate (glycolytic flux) dropped significantly from $2.02 \mathrm{mmol} / \mathrm{gDCW} / \mathrm{h}$ in JS122 to only 0.19 $\mathrm{mmol} / \mathrm{gDCW} / \mathrm{h}$ in JS124 (Table S1). After a $15 \mathrm{~h}$ fermentation, $41.6 \mathrm{~g} / \mathrm{L}$ glucose still remained unmetabolized (Fig. 2). 
We speculated that the drastic reduction in glucose consumption rate was due to an unbalanced redox metabolism, since the regeneration of $\mathrm{NAD}^{+}$via the formation of succinic acid had been blocked (17). We assayed the intracellular NADH/NAD ${ }^{+}$ratio of JS122 and JS124, and found that the intracellular NADH/NAD ${ }^{+}$ratio for JS124 (1.85) was much higher than for JS122 (0.06) (Fig. $3 \mathrm{~A})$.

\section{The PDHc is not a major contributor to NADH in resting cells.}

Unlike PDHc from E. coli or Lactococcus lactis, which is solely functional under aerobic conditions (18), the PDHc of C. glutamicum is also active under anaerobic conditions, which leads to formation of acetate (19). As the oxidation of pyruvate to acetate via PDHc contributes one additional NADH (Fig. 1), this could in principle perturb the redox balance and thus interfere with glycolysis. To address this potential problem, we replaced the E3 subunit (lpd) of the $C$. glutamicum PDHc with its E. coli counterpart.

The growth of the resultant strain JS125, which does not carry the ethanol plasmid, was slow on glucose probably due to suboptimal expression of the E. coli lpd. After a $40 \mathrm{~h}$ aerobic cultivation, the final cell density $\left(\mathrm{OD}_{600}\right)$ of JS125 only reached 0.36 in comparison to 11.7 for the parent strain JS119. To improve the growth of JS125 on minimal medium with glucose, we performed adaptive laboratory evolution for JS125 on the CGXII medium with 2\% glucose. After a short-term evolution ( 106 generations), several fast-growing strains were isolated (Fig. 4A). We sequenced the genome of the adapted strain JS125A, and identified only a single nucleotide substitution, $\mathrm{C} \rightarrow$ T, 15 bases upstream the start codon of $l p d$ in JS125.

Subsequently we introduced the ethanol plasmid pJS115 into this adapted strain and the outcome was strain JS133, which was characterized. Fig. 2D shows that JS133 only generates small amounts of acetate, and $0.3 \%$ of the consumed glucose ends up as acetate compared to 5\% for JS124. The 
ethanol yield for JS133 on glucose was $77.3 \%$. However, the replacement of the E3 subunit of PDHc only slightly decreased the intracellular NADH/NAD ${ }^{+}$ratio in the resting cells (Fig. 3A), and the glucose consumption rate of JS133 was not improved compared to that of JS124 (Fig. 2A).

\section{Deletion of the $z w f$ gene in JS133 boosts the glycolytic flux.}

In JS133 we had blocked NAD ${ }^{+}$regeneration by deleting $l d h A$ and $m d h$, reconstituted PDHc and subsequently introduced the ethanol plasmid, which in principle should restore the redox balance. However, the outcome of our experiments indicated the presence of other pathways able to affect the NADH/NAD ${ }^{+}$ratio.

It has been reported that during anaerobic fermentation, $C$. glutamicum exhibits a higher sugar consumption rate on fructose compared to glucose, which contrasts the observations made during aerobic growth (20). Furthermore, it is known that the PPP is bypassed when fructose is metabolized by $C$. glutamicum $(21,22)$. We decided to test whether the negative effects on glycolysis could be alleviated by using fructose as a carbon source instead of glucose. Indeed, JS133 could metabolize fructose faster than glucose and also the ethanol yield was improved on fructose. Using the same initial sugar concentration (50 g/L), JS133 consumed $18.66 \pm 4.01 \mathrm{~g}$ fructose and produced $12.95 \pm 2.85 \mathrm{~g}$ ethanol after $72 \mathrm{~h}$ of biocatalysis, whereas JS133 only consumed $9.97 \pm 1.16 \mathrm{~g}$ glucose and produced $6.56 \pm 1.25 \mathrm{~g}$ ethanol. This raised the question of whether the PPP could have an effect on glycolytic flux in JS133.

This prompted us to inactivate the first enzyme of the oxidative PPP, glucose-6-phosphate dehydrogenase, which is encoded by $z w f$. The modification indeed boosted sugar consumption and ethanol production for the resting cells. As shown in Fig. 2A, the glucose consumption rate of JS134 was enhanced 2.6 fold when compared to JS133. The ethanol yield reached as high as $92 \%$ of the theoretical maximum, a 29\% increase compared to the starting strain JS122. These data 
demonstrate that the PPP indeed is a source of reducing power for resting C. glutamicum. It is wellknown that the main role of the PPP is NADPH generation, however, for the resting cells we detected a low transhydrogenase activity $\left(3.95 \pm 1.21 \mu \mathrm{mol} \mathrm{min}^{-1} \mathrm{~g}^{-1}\right)$, which might explain the formation of NADH.

Disrupting the PPP in JS134 prevented growth in minimal medium, and to restore growth we found that it was necessary to add a nitrogen source such as yeast extract (YE) or corn steep liquor (CSL). By adding $2 \%$ CSL the biomass density was able to reach $\mathrm{OD}_{600} 21.8$ (Fig. 4B).

\section{Comparison of cofactor balance in different ethanol-producing strains.}

We measured the intracellular cofactor levels of different $C$. glutamicum constructs during ethanol production under anoxic conditions. In Fig. $3 \mathrm{~A} \& \mathrm{~B}$, the changes in NADH/NAD ${ }^{+}$, $\mathrm{NADPH} / \mathrm{NADP}^{+}$, and ATP/ADP ratios with different metabolic modifications are displayed. As we mentioned earlier, deletion of $m d h$ resulted in a sharp rise in the NADH/NAD ${ }^{+}$ratio to 1.85 in JS124 from 0.06 in JS122, and the $m d h$ mutant had a greatly reduced glucose consumption rate (Fig. 2A). This modification drastically reduced the ATP/ADP ratio (Fig. 3B). Interestingly, the increase in $\mathrm{NADH} / \mathrm{NAD}^{+}$ratio coincided with a considerable increase in the NADPH/NADP ${ }^{+}$ratio. The replacement of the E3 subunit of PDHc (JS133) only slightly reduced the NADH/NAD ${ }^{+}$ratio, and appeared not to release the hampering effect on glycolysis. However, the deletion of $z w f($ JS134) reduced the NADPH/NADP ${ }^{+}$ratio to 0.05 , and was accompanied by a reduction of NADH/NAD ${ }^{+}$ ratio to 0.46. Blocking the PPP boosted glucose consumption in JS134, and the ATP/ADP ratio recovered to 1.34 .

\section{RNA-seq analysis reveals the impact of $z w f$ inactivation on energy metabolism.}

As the deletion of $z w f$ had a great impact on the cofactor balance and cellular energy status of $C$. glutamicum under anoxic conditions, we further investigated the impact on the transcriptional level 
carrying out a transcriptome analysis for JS133 and JS134 (JS133 with zwf deletion). For each strain three independent replicate experiments were included, and it was shown that JS133 and JS134 had quite different transcriptomic profiles, where the differentially expressed genes in JS133 clustered separately from those of JS134 (Fig. 5A). When compared to JS133, a total of 592 and 334 genes had been down-regulated and up-regulated (log2-fold-change $>1$, p-value $<0.05$ ) in JS134, respectively (see all the differentially expressed genes in Table S3, S4). As expected, the $z w f$ gene was 9.0-fold $(\log 2)$ down-regulated in JS134. Among the 592 down-regulated genes used for Gene Ontology (GO) analysis, $13.7 \%$ genes could be allocated to the term "ATP binding" (Fig. 5B). These genes were mainly involved in ATP-dependent process such as transport, helicase, kinase and synthase. In terms of "proton-transporting ATP synthase activity", seven genes encoded subunits of the F0F1-ATP synthase, and they were down-regulated from 3.0 to 1.5 folds $(\log 2)$ in JS134. Interestingly, the term "nitrate reductase activity" was also enriched, even though nitrate was not present in the medium used.

Of the up-regulated genes in JS134, most could be allocated to the term "DNA binding", where most of the genes were involved in cell division and transcriptional regulation. The gapA gene, which encodes glyceraldehyde-3-phosphate dehydrogenase in glycolysis, appeared in the term "NADP binding" and was also up-regulated.

\section{Expanding the repertoire - D-lactate production.}

After demonstrating that efficient high-yield ethanol production could be accomplished using JS134, we decided to investigate whether other pyruvate-derived chemicals could be made using the strain deficient in malate dehydrogenase and glucose-6-phosphate dehydrogenase. To achieve a high-yield production of D-lactate in C. glutamicum, we overexpressed the D-lactate dehydrogenase from Lactobacillus delbruckii in the strain JS132. The productivity of D-lactate in the resulting strain 
JS138 was slightly lower than for the strain carrying only deletions in $l d h A$ and $p p c$ (JS137), but the yield for JS138 reached $98 \%$ of the theoretical, which is 14\% higher when compared to JS137 (Fig. 6). To the best of our knowledge, this is the highest yield of D-lactate reported this far for $C$. glutamicum.

\section{Increasing resource utilization using dairy waste feedstock.}

We achieved extremely high-yield production of ethanol and D-lactate from glucose, which stimulated us to explore the actual applications by harnessing this PPP - disrupted platform strain JS132. Since we have previously engineered $C$. glutamicum into being able to metabolize lactose, and this was done by introducing the transporter LacS, the $\beta$-glucosidase LacZ, and the Leloir pathway (GalMKTE), which resulted in strain JS112 (Fig. 7A). Lactose is available in large amounts in whey permeate (WP), which are abundantly generated as waste by dairy industry in most parts of the world. We first optimized the growth of JS132 on WP with different types of nitrogen source. The pure WP did not support its growth well, and the final cell density on this substrate only reached $2.7\left(\mathrm{OD}_{600}\right)$ after $24 \mathrm{~h}$. Adding the minimal medium salts improved the cell density to $5.1\left(\mathrm{OD}_{600}\right)$. Adding organic nitrogen sources, either $1 \% \mathrm{YE}$ or 5\% CSL resulted in a significant increase in biomass and the cell densities could reach $35\left(\mathrm{OD}_{600}\right)$ and $39\left(\mathrm{OD}_{600}\right)$, respectively (Fig. S1).

\section{Production of chemicals from lactose - containing dairy wastes.}

Using the pure WP as the substrate, we achieved $48 \mathrm{~g} / \mathrm{L}$ ethanol from $106 \mathrm{~g} / \mathrm{L}$ lactose with a yield of $85 \%$ (of the theoretical maximum) on JS134 compared with only $66 \%$ on JS122, which coproduced $37 \mathrm{~g} / \mathrm{L}$ ethanol and $23 \mathrm{~g} / \mathrm{L}$ succinate (Fig. 7B). We also noticed the productivity was reduced for JS134 due to the lower glycolytic flux, which was also the case in glucose medium. Similarly, we got $92 \mathrm{~g} / \mathrm{L}$ D-lactate with a yield of $86 \%$ on JS138. There was a combination of 79 
g/L D-lactate and $12 \mathrm{~g} / \mathrm{L}$ succinate on JS137 with a yield of 73\% for D-lactate (Fig. 7C). The productivity, however, was reduced to $1.64 \mathrm{~g} / \mathrm{L} / \mathrm{h}$ in JS138 from $2.19 \mathrm{~g} / \mathrm{L} / \mathrm{h}$ in JS137.

We further constructed strain JM141 to produce alanine from lactose by overexpressing alanine dehydrogenase in our $z w f$-inactivated strain JS132. After $75 \mathrm{~h}$, we achieved $89 \mathrm{~g} / \mathrm{L}$ alanine from 110 g/L lactose in WP with a yield of 78\% compared with $70 \mathrm{~g} / \mathrm{L}$ (Yield: 61\%) on JM140 (Fig. 7D). The productivity was reduced a little from $1.44 \mathrm{~g} / \mathrm{L} / \mathrm{h}$ to $1.37 \mathrm{~g} / \mathrm{L} / \mathrm{h}$. The accumulation of galactose and succinate were observed for both strains (data not shown). These data demonstrate that inactivation of the PPP is a useful strategy for enhancing the yield for producing these valuable chemicals from WP. The yield improvement was $20 \%$ for ethanol, $13 \%$ for D-lactate and $17 \%$ for alanine, respectively.

\section{Discussion}

A major challenge when using resting $C$. glutamicum for producing fuels and chemicals is how to achieve a high yield. In previous studies where $C$. glutamicum was tailored into producing compounds via redox balanced reactions, lactate, acetate and succinate were three major byproducts that affected the final product yield $(11,12,17,23)$. By deleting $l d h A$, the lactate formation could be eliminated, while aerobic growth remained unaffected. Under anaerobic conditions, the loss of lactate dehydrogenase was compensated by redirecting the flux to other compounds that require NADH for biosynthesis, typically succinate (9). Glycolysis and thus sugar consumption in $C$. glutamicum have been found to be negatively affected by a high intracellular $\mathrm{NADH} / \mathrm{NAD}^{+}$ratio, due to the inhibition of glyceraldehyde 3-phosphate dehydrogenase $(24,25)$. This is exactly what we observed in this study. When we knocked out the $m d h$ gene in our ethanol producing strain JS122 to eliminate succinate formation, the intracellular NADH/NAD ${ }^{+}$ratio 
increased dramatically and the glycolytic flux was hampered (Fig. 2A \& 3A) with a low cellular energy status as the direct consequence of this (Fig. 3B). Other researchers have suggested that unidentified metabolic pathways could contribute to the surplus NADH in C. glutamicum under anoxic conditions (11). We first suspected that the formation of acetate under anoxic conditions might be one reason, as the oxidation of pyruvate via pyruvate dehydrogenase generates NADH, which could elevate the NADH/NAD ${ }^{+}$ratio (Fig. $1 \& 3 \mathrm{~A}$ ). Pyruvate dehydrogenase is a complex enzyme composed of three subunits E1, E2, and E3 (19). Deletion of the E1 subunit can inactivate PDHc and block the conversion of pyruvate to acetate (19). Without PDHc, the aerobic growth of $C$. glutamicum requires exogenous acetate or ethanol as a precursor for synthesis of the essential acetyl-CoA (26). It has a negative effect on glucose consumption with the co-metabolism of acetate under aerobic conditions (27). In this study, we replaced the native E3 subunit with the one from $E$. coli PDHc, which only functions under aerobic conditions $(26,36)$. By exchanging the lpd gene encoding the E3 subunit, we successfully eliminated most of the acetate formation (maybe little can still be formed by pyruvate:quinone oxidoreductase) (Fig. 2D). This modification increased the ethanol yield, but did not improve the glucose consumption rate, and only a slight drop in NADH/NAD ${ }^{+}$ratio was achieved (Fig. 3A).

Wild-type C. glutamicum strain metabolizes glucose faster $\left(5.25 \mathrm{mmol} \mathrm{g}^{-1} \mathrm{~h}^{-1}\right)$ than fructose $(4.42$ mmol g${ }^{-1} h^{-1}$ ) when growing aerobically (20), but the opposite behavior has been observed under anoxic conditions (29), and this attracted our attention. When fructose was used as the sole carbon source, four times less of the sugar taken up was channeled into the PPP when compared to glucose, and as a consequence less NAPDH was generated (18). We found that JS133 exhibited a significantly higher ethanol production rate on fructose than on glucose, and we speculated that the PPP somehow might be involved in regulating the glycolysis under anoxic conditions. After inactivating glucose-6-phosphate dehydrogenase, a large reduction in the intracellular 
$\mathrm{NADPH} / \mathrm{NADP}^{+}$ratio was achieved, and surprisingly the NADH/NAD ${ }^{+}$ratio was also reduced (Fig.

3A). Blocking the PPP greatly increased the glycolytic flux as well as the ATP/ADP ratio in JS134

(Fig. 2A, 3B). Under anoxic conditions, 5\% glucose was metabolized through the PPP compared to 95\% through glycolysis in C. glutamicum, although the NAPDH-consuming anabolism was halted (30).

In this study, we also found the interconnections between NADPH and NADH during the anoxic catabolism of sugars in C. glutamicum. When we blocked the formation of succinate, an increase in the NADH/NAD ${ }^{+}$ratio was accompanied by an increase in the NADPH/NADP ${ }^{+}$(Fig. 3A). In the opposite way, when we blocked the PPP to reduce the NADPH/NADP ${ }^{+}$ratio, the NADH/NAD ${ }^{+}$ ratio concurrently decreased (Fig. 3A). A similar phenomenon was observed in Yamamoto et al.'s study for alanine production in C. glutamicum (31). When they overexpressed the glycolytic genes $g a p A, p f k$, and $p g i$, individually, to enhance glucose consumption under oxygen deprivation conditions, the NADPH/NADP ${ }^{+}$ratio changed proportionally with the change of NADH/NAD ${ }^{+}$ ratio, even though the carbon flux into the PPP did not change significantly. There might be several explanations for this. As we know, transhydrogenase participates in the interconversion of NADPH and NADH in microbes to maintain the intracellular redox hemostasis (32). As it was shown in the resting Bacillus subtilis, the PPP generated surplus NADPH and it was expected the transhydrogenation activity was responsible for the conversion of NADPH to NADH in order to maintain the intracellular redox hemostasis, though the responsible gene was not identified (33). Although the gene encoding transhydrogenase is not found in C. glutamicum (34), we did detect a minor transhydrogenase activity in the non-growing $C$. glutamicum cells under anoxic condition. It might also be possible that the NADPH-dependent malate enzyme together with malate:quinone oxidoreductase and oxaloacetate dehydrogenase could form a metabolic cycle and exhibit transhydrogenase activities responsible for generating NADH from NADPH (35). Another 
explanation might be due to the promiscuity of glucose-6-phosphate dehydrogenase ( $z w f$-encoding), which may accept $\mathrm{NAD}^{+}$for generating NADH directly under some conditions, although the purified glucose-6-phosphate dehydrogenase did not display a $\mathrm{NAD}^{+}$dependent activity in vitro (36). The glucose-6-phosphate dehydrogenase from both Z. mobilis and Bacillus subtilis are known to be able to generate $\mathrm{NADH}(37,38)$.

RNA-seq analysis also revealed a dramatic alteration of gene expression in response to the blockage of PPP. When $z w f$ was deleted, the expression of the $\mathrm{F}_{1} \mathrm{~F}_{0}$-ATP synthase was significantly downregulated in JS134 (Fig. 5), which indicated that the energy starvation caused by cofactor imbalance could be mitigated by blocking PPP. Simultaneously, the expression of the nitrate reductase operon was also regulated in JS134. It is known that $C$. glutamicum is capable of anaerobic respiration using nitrate as a terminal electron acceptor (39). Even though, nitrate was not provided in the fermentation broth, a down-regulation of nitrate reductase in the strain lacking zwf indicated that the $\mathrm{NADH} / \mathrm{NAD}^{+}$ratio could be involved in regulating expression of this gene. Of the up-regulated genes, we found the key glycolytic enzyme glyceraldehyde-3-phosphate dehydrogenase was upregulated after deleting $z w f$. The observation was consistent to previous studies that have shown that expression of glyceraldehyde-3-phosphate dehydrogenase is inhibited by high NADH/NAD ${ }^{+}$ratios under anoxic conditions (40). Overall, the results from the transcriptional analysis were congruent with the changes observed in the fermentation physiology, where deletion of $z w f$ relieved energy starvation and cofactor imbalance under anoxic conditions.

In this study, we successfully pinpointed the pathway responsible for the high NADH/NAD ${ }^{+}$ratio observed in C. glutamicum under anoxic conditions. This knowledge can be harnessed to engineer C. glutamicum mutants producing high yield of chemicals via redox-balanced reactions, which has its intrinsic challenges (11). In a previous study, where a $\Delta p p c \Delta l d h A$ mutant of $C$. glutamicum was used for producing D-lactate, only about $86 \%$ of the theoretical yield could be accomplished from 
glucose (23). Here, by combining a modified pyruvate dehydrogenase and PPP inactivation, a yield to $98 \%$ was attained, which is among the highest D-lactate yields achieved using microbial fermentation (41).

By harnessing the fundamental discovery that the disruption of PPP strategy can benefit high-yield production, we further demonstrate its applications on the converstion of lactose, which is rich in dairy wastes, into valuable compounds. Growth of the PPP - disrupted strains could be restored on the substrate WP with CSL. We finally achieved high-yield production of ethanol, D-lactate and alanine on WP. Previously, we achieved a yield of $88 \%$ of the theoretical using JS122 on delactosed WP (DWP) provided by MS Iceland Dairies (15) and the yield on WP provided by Arla Food Ingredients (Denmark) in the present work was only 65\%. As the biotin concentration is much higher in WP than DWP and biotin is the cofactor for pyruvate carboxylase, which requires for the production of succinate from pyruvate. So it might explain that we got a lower yield of ethanol on WP using the same strain. We also noticed that the productivity was lowered in our PPP - disrupted strains and this can be complemented in the future studies by overexpressing the glycolytic enzymes or employing the ATP draining strategies through for instance, overexpression of the F1-ATPase (42).

\section{Materials and methods}

\section{Bacterial strains, plasmids.}

All bacterial strains and plasmids used or constructed in this study are listed in Table 1.

\section{Growth medium and conditions.}

E. coli strains were grown aerobically in Luria-Bertani broth (LB) at $37^{\circ} \mathrm{C}$, and C. glutamicum strains were cultivated in Brain Heart Infusion (Oxoid) broth (BHI) at $30^{\circ} \mathrm{C}$ with $200 \mathrm{rpm}$ shaking. 
For ethanol and D-lactate production, C. glutamicum strains were aerobically cultivated in CGXII medium supplemented with $5 \%$ glucose or fructose, and if necessary, $0.5 \%$ yeast extract (YE) was added for the growth of $z w f$ inactivated strains. When appropriate, kanamycin was added to a concentration of $50 \mu \mathrm{g} / \mathrm{mL}$ for $E$. coli and $25 \mu \mathrm{g} / \mathrm{mL}$ for $C$. glutamicum, and spectinomycin was used at a concentration of $100 \mu \mathrm{g} / \mathrm{mL}$ for E.coli and $50 \mu \mathrm{g} / \mathrm{mL}$ for $C$. glutamicum. For gene deletion or replacement in C. glutamicum, $10 \%$ sucrose was used for counter-selection. Cell growth was monitored by measuring the optical density at $600 \mathrm{~nm}\left(\mathrm{OD}_{600}\right)$ of the culture broth using a UV1800 spectrophotometer (Shimadzu, Japan). The dry cell weight was calculated based on DCW $(\mathrm{g} / \mathrm{L})=$ $\mathrm{OD}_{600} \times 0.3(43)$

\section{Construction of plasmids and strains.}

All molecular manipulations were performed according to the standard protocols (44) and Handbook of Corynebacterium glutamicum (45). All plasmids/strains constructed in this study were verified by Sanger Sequencing (Macrogen, Korea).

C. glutamicum mutants carrying gene deletions in $m d h$ and $z w f$ and mutants where the E. coli lpd gene substituted the native $l p d$, were constructed via a two-step homologous recombination procedure as described previously (45) using the vector pK18mobsacB (46). Plasmids were transformed into $C$. glutamicum by electroporation.

For the construction of pK18-mdh, the regions up- and downstream (approximately 750-bp each) of the $m d h$ gene to be deleted were amplified (primers used can see Table S2). The resulting DNA fragments were cloned into pK18mobsacB through Gibson assembly. The plasmid pK18-zwf was constructed in a similar manner. A gBlock gene fragment containing the regions up- and downstream of $z w f$ was synthesized by Integrated DNA Technologies (sequences can see Fig. S3), and then cloned into pK18mobsacB. 
Plasmid pK18-lpd(E) was constructed in order to replace the chromosomal lpd gene from $C$. glutamicum. For this purpose, a gBlock gene fragment containing the $l p d$ gene of $E$. coli flanked by the up- and downstream regions ( approximately 750-bp each) of the lpd gene of C. glutamicum was synthesis by Integrated DNA Technologies (sequences can see Fig. S2), in which the lpd gene starts with GTG codon, and then cloned into pK18mobsacB.

For the construction of the expression plasmid pJS136 (D-lactate) and pJM140 (alanine), the 1.2-kb L. delbrueckii ldhA gene coding D-LDH was amplified using L. delbrueckii chromosomal DNA as the template, and the 1.1-kb alaDH encoding alanine dehydrogenase from Lysinibacillus sphaericus was synthesized by Genscript (Piscataway, US). The resulting fragments were, individually, inserted into the vector pEC-XK99E (47) through Gibson assembly.

\section{Conditions for ethanol and D-lactate production using the minimal medium.}

Ethanol production under oxygen deprivation was performed as previously described, with minor alterations (12). C. glutamicum strains were aerobically cultivated at $30^{\circ} \mathrm{C}$ for $16-20 \mathrm{~h}$ in a $1 \mathrm{~L}$ flask containing $200 \mathrm{~mL}$ of CGXII medium supplemented with $50 \mathrm{~g} / \mathrm{L}$ glucose or fructose, if necessary, 0.5\% YE was added. 0.1 mM IPTG was added in the medium for JS137 and JS138. Cells were harvested by centrifugation $\left(5000 \times \mathrm{g}, 4^{\circ} \mathrm{C}, 10 \mathrm{~min}\right.$.) and then resuspended in fresh CGXII medium with $50 \mathrm{~g} / \mathrm{L}$ glucose or fructose to a concentration corresponding to $10 \mathrm{~g}$ DCW/L. Temperature was maintained at $30^{\circ} \mathrm{C}$. Oxygen deprivation was achieved with high cell density, no aeration, and gentle agitation.

The procedure for D-lactate production was similar to ethanol production, however, to maintain $\mathrm{pH}$ the medium was supplemented with $40 \mathrm{~g} / \mathrm{L} \mathrm{CaCO}_{3}$.

\section{Procedure for adaptive laboratory evolution.}


The evolution was conducted using a serial-transfer regime with strain JS125, a C. glutamicum derivative in which the genes $l d h A, p p c, m d h$ were deleted and the native $l p d$ gene was replaced with the $l p d$ gene from E. coli. A single colony of JS125 was inoculated into a test tube containing $5 \mathrm{~mL}$ CGXII medium with $2 \%$ glucose, and cultivated at $30^{\circ} \mathrm{C}$ with $200 \mathrm{rpm}$ shaking. When the culture entered the stationary phase, $0.05 \mathrm{~mL}$ of culture was transferred into a new test tube with the same medium, which was equal to a 6.64-generation adaptation. Each week, a copy of the culture was saved in $25 \%$ glycerol at $-80^{\circ} \mathrm{C}$. The growth performance of JS125 was regularly checked. After a 100-generation adaptive evolution, culture from the final tube was streaked on the CGXII glucose plate, and one fast-growing single colony was isolated, and was designated as JS125A.

\section{Production of ethanol, D-lactate and alanine from whey permeate.}

Whey permeate (WP) is provided by the dairy company Arla Foods Ingredients Group P/S (Viby, Denmark). It is the by-product of dairy industry for producing whey proteins from whey, which is obtained in the cheese making process. WP has more than $10 \%(w / v)$ lactose. We tested the growth of JS134 on 50\% WP (diluted with water) with different types of nitrogen sources. Corn steep liquor (CSL) with 50\% solid content, which was purchased from Sigma-Aldrich (St. Louis, MO), was centrifuged for 10 mins at 5,000 $\times g$ and the supernatant was used. The minimal medium salts contain $\left(\mathrm{NH}_{4}\right)_{2} \mathrm{SO}_{4}(7 \mathrm{~g} / \mathrm{L}), \mathrm{FeSO}_{4}(20 \mathrm{mg} / \mathrm{L}), \mathrm{MnSO}_{4}(2 \mathrm{mg} / \mathrm{L})$ and the trace element solution from the CGXII medium. The $\mathrm{pH}$ for all the medium was adjusted to 7.0. A single colonly of JS134 was inoculated into $25 \mathrm{~mL}$ medium in $100 \mathrm{~mL}$ flask and cultivated at $30^{\circ} \mathrm{C}$ with $200 \mathrm{rpm}$ shaking. The cell density $\left(\mathrm{OD}_{600}\right)$ was measured after $24 \mathrm{~h}$.

For the production of ethanol, D-lactate and alanine, we grew the relevant strains in $1 \mathrm{~L}$ flask containing $200 \mathrm{~mL} 50 \% \mathrm{WP}$, MMS and 1\% YE (for easy manipulation instead of CSL). The cells 
were collected after $20 \mathrm{~h}$ and then resuspended in $50 \mathrm{~mL}$ pure WP medium to achieve a cell concentration of $20 \mathrm{~g} \mathrm{DCW} / \mathrm{L}$. The $\mathrm{pH}$ of the fermenation was maintained at $7.0 \mathrm{using}$ the Biostat A (Sartorious, Germany) pH-control system by supplementing $5 \mathrm{M}$ ammonia solution.

\section{RNA sequencing.}

When we prepared the samples for transcriptomic analysis, we first grew the strains JS133 and JS134 in exactly the same medium that is CGXII medium with $0.5 \%$ YE. Then we respended the cells in fresh CGXII medium with 5\% glucose. After $3 \mathrm{~h}$ incubation under anaerobic conditions, we collected $200 \mu \mathrm{L}$ culture that was spiked in $800 \mu \mathrm{L}$ RNAlater solution (ThermoFisher Scientific). After centrifugation at 12,000 g for $2 \mathrm{~min}$, the supernatant was discarded, and the pellet was used for extracting total RNA using the RNeasy Mini kit (Qiagen) according to the manufacture's instruction. The integrity of RNA was determined by a 2100 BioAnalzyer (Agilent). Commercial service of library preparation and sequencing were provided by BGI China. The sequencing was performed on a BGIseq 500 next-generation sequencer, from which datasets consisted of at least 20 M clean reads (single-paired) per sample were obtained. Afterwards, adaptor sequences, contamination and low-quality reads were removed from the raw reads. Read trimming, mapping and statistical analysis were performed on CLC Genomics Workbench. For the differentially overexpressed genes, the heatmap for JS133 and JS134 (three independents each) was made using the pheatmap package in R (49) and Go enrichment analysis was conducted using the DAVID tools $(49,50)$. All the raw sequence read and processed data were deposited in Gene Expression Omnibus (GEO) at NCBI under the accession NO. GSE143977 (token for reviewer access: cdgjcuiqldwbtgl).

\section{Analytical techniques.}


I) Product formation and sugar consumption. Culture samples were withdrawn, centrifuged $\left(15,000 \times \mathrm{g}, 4^{\circ} \mathrm{C}, 5 \mathrm{~min}.\right)$, and the supernatant saved at $-20^{\circ} \mathrm{C}$ for later analysis. Sugar, ethanol, Dlactate, succinate, acetate and glycerol were quantified using an Ultimate 3000 high-pressure liquid chromatography system (Dionex, Sunnyvale, USA) equipped with an Aminex HPX-87H column (Bio-Rad, Hercules, USA) and a Shodex RI-101 detector (Showa Denko K.K., Tokyo, Japan). The column oven temperature was set at $60^{\circ} \mathrm{C}$, the mobile phase was at $5 \mathrm{mM} \mathrm{H}_{2} \mathrm{SO}_{4}$, and the flow rate was $0.5 \mathrm{~mL} / \mathrm{min}$. The alanine concentration was measured using the alanine colorimetric kit (VWR No: BIOVK652-100).

\section{II) $\mathbf{N A D}(\mathbf{P}) \mathbf{H} / \mathrm{NAD}(\mathbf{P})^{+}$ratio. To measure intracellular $\mathrm{NAD}^{+}, \mathrm{NADH}, \mathrm{NADP}^{+}, \mathrm{NADPH}$} concentrations, cell extraction was performed as follows. $\mathrm{NAD}(\mathrm{P}) \mathrm{H}$ and $\mathrm{NAD}(\mathrm{P})^{+}$concentrations were determined at $3 \mathrm{~h}$ during ethanol production. The collected samples were immediately quenched by mixing with $1.0 \mathrm{~mL}$ cold methanol $\left(-80^{\circ} \mathrm{C}\right)$, and the resultant cell suspension $(0.5 \mathrm{~mL})$ was mixed vigorously with $0.5 \mathrm{~mL}$ chloroform and $0.5 \mathrm{~mL} \mathrm{H}_{2} \mathrm{O}\left(-20^{\circ} \mathrm{C}\right)$ to disrupt cells. After incubation for $60 \mathrm{~min}$ at $-20^{\circ} \mathrm{C}$, the sample solution was centrifuged $\left(20,000 \times \mathrm{g}, 4^{\circ} \mathrm{C}, 5 \mathrm{~min}\right.$.), and an aliquot of the upper layer $(50 \mu \mathrm{L})$ was mixed with $50 \mu \mathrm{L} \mathrm{H}_{2} \mathrm{O}$ or standard mixture solutions. The mixtures were further centrifuged $\left(20,000 \times \mathrm{g}, 4^{\circ} \mathrm{C}, 5 \mathrm{~min}\right)$, and the resultant supernatant was analyzed using an NAD(P)/NAD(P)H Assay Kit (Sigma-Aldrich, St. Louis, MO, USA).

III) ATP/ADP. Samples were collected at $3 \mathrm{~h}$ during ethanol production. Cell extraction was performed as previously described (51). Cultures $(5 \mathrm{~mL})$ were quenched with 1 volume $80^{\circ} \mathrm{C}$ phenol. After being centrifuged (4,000×g, $10 \mathrm{~min}$.), the water phase was transferred into a new tube and extracted with 1 volume of chloroform twice. ATP was measured using a BioThema ATP kit HS, and ADP was converted into ATP by $1 \mathrm{mM}$ PEP and $1 \mathrm{U}$ pyruvate kinase. The luminescence was subsequently measured on a Tecan Infinite M200 Pro microplate reader. 
IV) Measurement of transhydrogenase activity. Samples were collected at $3 \mathrm{~h}$ during ethanol production under oxygen deprivation conditions. Cell suspensions were disrupted by bead beating 459 using a FastPrep system (MP Biomedicals) with acid-washed glass beads (106 $\mu \mathrm{m}$, Sigma-Aldrich 460 prod. No.: G4649). The transhydrogenase activity was measured according to the procedure described by Sauer et al. (32) . Briefly, the absorbance at $375 \mathrm{~nm}$ was monitored using a Tecan Infinite M200 Pro microplate reader at $25^{\circ} \mathrm{C}$ in a mixture containing $50 \mathrm{mM}$ Tris $\cdot \mathrm{HCl}(\mathrm{pH} 7.6), 2$ $\mathrm{mM} \mathrm{MgCl} 2,500 \mu \mathrm{M}$ NADPH, $1 \mathrm{mM}$ 3-acetylpyridine adenine dinucleotide, and 10-100 $\mu \mathrm{L}$ cell extract. The specific activity was obtained through dividing the measured slope by the protein concentration. Protein concentrations were determined using Bradford according to the manual (Sigma-Aldrich).

\section{Supplementary material}

Supplementary File 1

\section{Acknowledgements}

This work was supported by the DTU PoC Fund ("Sweet as Sugar" project), the Danish Dairy (Grant No. 6150-00036B). 


\section{References}

478 1. Becker J, Wittmann C. 2012. Systems and synthetic metabolic engineering for amino acid production - the heartbeat of industrial strain development. Curr Opin Biotechnol 23:718-26.

2. Becker J, Giebelmann G, Hoffmann S, Wittmann C. 2018. Corynebacterium glutamicum for sustainable bioproduction: from metabolic physiology to systems metabolic engineering. Adv Biochem Eng Biotechnol 162:217-263.

3. Inui M, Toyoda K. 2013. Corynebacterium glutamicum: Biology and Biotechnology.

4. Becker J, Wittmann C. 2017. Industrial microorganisms: Corynebacterium glutamicum. Ind Biotechnol 183-220.

Becker J, Wittmann C. 2012. Bio-based production of chemicals, materials and fuels Corynebacterium glutamicum as versatile cell factory. Curr Opin Biotechnol 23:631-40.

9. Inui M, Murakami S, Okino S, Kawaguchi H, Vertès A a, Yukawa H. 2004. Metabolic analysis of Corynebacterium glutamicum during lactate and succinate productions under oxygen deprivation conditions. J Mol Microbiol Biotechnol 7:182-96.

10. Okino S, Noburyu R, Suda M, Jojima T, Inui M, Yukawa H. 2008. An efficient succinic acid production process in a metabolically engineered Corynebacterium glutamicum strain. Appl Microbiol Biotechnol 81:459-464.

. Jojima T, Fujii M, Mori E, Inui M, Yukawa H. 2010. Engineering of sugar metabolism of Corynebacterium glutamicum for production of amino acid L-alanine under oxygen deprivation. Appl Microbiol Biotechnol 87:159-65.

12. Inui M, Kawaguchi H, Murakami S, Vertès AA, Yukawa H. 2004. Metabolic engineering of Corynebacterium glutamicum for fuel ethanol production under oxygen-deprivation conditions. J Mol 
Microbiol Biotechnol 8:243-54.

13. Sakai S, Tsuchida Y, Okino S, Ichihashi O, Kawaguchi H, Watanabe T, Inui M, Yukawa H. 2007. Effect of lignocellulose-derived inhibitors on growth of and ethanol production by growth-arrested Corynebacterium glutamicum R. Appl Environ Microbiol 73:2349-2353.

14. Jojima T, Noburyu R, Sasaki M, Tajima T, Suda M, Yukawa H, Inui M. 2015. Metabolic engineering for improved production of ethanol by Corynebacterium glutamicum. Appl Microbiol Biotechnol 99:1165-1172.

15. Shen J, Chen J, Jensen PR, Solem C. 2019. Development of a novel, robust and cost-efficient process for valorizing dairy waste exemplified by ethanol production. Microb Cell Fact 18:51.

16. Peters-Wendisch PG, Kreutzer C, Kalinowski J, Pátek M, Sahm H, Eikmanns BJ. 1998. Pyruvate carboxylase from Corynebacterium glutamicum: characterization, expression and inactivation of the pyc gene. Microbiology 144:915-927.

17. Wieschalka S. 2012. Engineering Corynebacterium glutamicum as a designer-bug for the bio-based production of chemical building blocks and biofuel. Open Access Repositorium der Universität Ulm. Dissertation.

18. Snoep JL, de Graef MR, Westphal a H, de Kok A, Teixeira de Mattos MJ, Neijssel OM. 1993. Differences in sensitivity to NADH of purified pyruvate dehydrogenase complexes of Enterococcus faecalis, Lactococcus lactis, Azotobacter vinelandii and Escherichia coli: implications for their activity in vivo. FEMS Microbiol Lett 114:279-83.

19. Yasuda K, Jojima T, Suda M, Okino S, Inui M, Yukawa H. 2007. Analyses of the acetate-producing pathways in Corynebacterium glutamicum under oxygen-deprived conditions. Appl Microbiol Biotechnol 77:853-60.

20. Dominguez H, Cocaign-Bousquet M, Lindley ND. 1997. Simultaneous consumption of glucose and fructose from sugar mixtures during batch growth of Corynebacterium glutamicum. Appl Microbiol Biotechnol 47:600-603.

21. Dominguez H, Rollin C, Guyonvarch A, Guerquin-Kern J, Bousquet M, D.Lindley N. 1998. Carbonflux distribution in the central metabolic pathways of Corynebacterium glutamicum during growth on fructose. Eur J Biochem 254:96-102.

22. Kiefer P, Heinzle E, Zelder O, Wittmann C. 2004. Comparative metabolic flux analysis of lysineproducing Corynebacterium glutamicum cultured on glucose or fructose. Appl Environ Microbiol 
70:229-239.

23. Okino S, Suda M, Fujikura K, Inui M, Yukawa H. 2008. Production of D-lactic acid by Corynebacterium glutamicum under oxygen deprivation. Appl Microbiol Biotechnol 78:449-454.

24. Danshina P V, Schmalhausen E V, Avetisyan A V, Muronetz VI. 2001. Mildly oxidized glyceraldehyde-3-phosphate dehydrogenase as a possible regulator of glycolysis. IUBMB Life 51:309-314.

25. Tsuge Y, Uematsu K, Yamamoto S, Suda M, Yukawa H, Inui M. 2015. Glucose consumption rate critically depends on redox state in Corynebacterium glutamicum under oxygen deprivation. Appl Microbiol Biotechnol 99:5573-5582.

26. Schreiner ME, Fiur D, Holátko J, Pátek M, Eikmanns BJ. 2005. E1 enzyme of the pyruvate dehydrogenase complex in Corynebacterium glutamicum: molecular analysis of the gene and phylogenetic aspects. J Bacteriol 187:6005-6018.

27. Blombach B, Schreiner ME, Holátko J, Bartek T, Oldiges M, Eikmanns BJ. 2007. L-valine production with pyruvate dehydrogenase complex-deficient Corynebacterium glutamicum. Appl Environ Microbiol 73:2079-84.

28. Kim Y, Ingram LO, Shanmugam KT. 2008. Dihydrolipoamide dehydrogenase mutation alters the NADH sensitivity of pyruvate dehydrogenase complex of Escherichia coli K-12. J Bacteriol 190:3851-3858.

29. Michel A, Koch-Koerfges A, Krumbach K, Brocker M, Bott M. 2015. Anaerobic growth of Corynebacterium glutamicum via mixed-acid fermentation. Appl Environ Microbiol 81:7496-7508.

30. Radoš D, Turner DL, Fonseca LL, Carvalho L, Blombach B, Eikmanns BJ, Neves AR, Santos H. 2014. Carbon flux analysis by $13 \mathrm{C}$ nuclear magnetic resonance to determine the effect of $\mathrm{CO}_{2}$ on anaerobic succinate production by Corynebacterium glutamicum. Appl Environ Microbiol 80:30153024.

31. Yamamoto S, Gunji W, Suzuki H, Toda H, Suda M, Jojima T, Inui M, Yukawa H. 2012. Overexpression of genes encoding glycolytic enzymes in Corynebacterium glutamicum enhances glucose metabolism and alanine production under oxygen deprivation conditions. Appl Environ Microbiol 78:4447-57.

32. Sauer U, Canonaco F, Heri S, Perrenoud A, Fischer E. 2004. The soluble and membrane-bound transhydrogenases UdhA and PntAB have divergent functions in NADPH metabolism of Escherichia 
coli. J Biol Chem 279:6613-6619.

33. Rühl M, Le Coq D, Aymerich S, Sauer U. 2012. 13C-flux analysis reveals NADPH-balancing transhydrogenation cycles in stationary phase of nitrogen-starving Bacillus subtilis. J Biol Chem 287:27959-70.

34. Kabus A, Georgi T, Wendisch VF, Bott. 2007. Expression of the Escherichia coli pntAB genes encoding a membrane-bound transhydrogenase in Corynebacterium glutamicum improves L-lysine formation. Appl Microbiol Biotechnol 75:47-53.

35. Sauer U, Eikmanns BJ. 2005. The PEP-pyruvate-oxaloacetate node as the switch point for carbon flux distribution in bacteria. FEMS Microbiol Rev 29:765-794.

36. Moritz B, Striegel K, De Graaf AA, Sahm H. 2000. Kinetic properties of the glucose-6-phosphate and 6-phosphogluconate dehydrogenases from Corynebacterium glutamicum and their application for predicting pentose phosphate pathway flux in vivo. Eur J Biochem 267:3442-3452.

37. Scopes RK. 1997. Allosteric control of Zymomonas mobilis glucose-6-phosphate dehydrogenase by phosphoenolpyruvate. Biochem J 326:731-5.

38. Black WB, Zhang L, Mak WS, Maxel S, Cui Y, King E, Fong B, Sanchez Martinez A, Siegel JB, Li H. 2020. Engineering a nicotinamide mononucleotide redox cofactor system for biocatalysis. Nat Chem Biol 16:87-94.

39. Nishimura T, Vertès AA, Shinoda Y, Inui M, Yukawa H. 2007. Anaerobic growth of Corynebacterium glutamicum using nitrate as a terminal electron acceptor. Appl Microbiol Biotechnol 75:889-897.

40. Tsuge Y, Uematsu K, Yamamoto S, Suda M, Yukawa H, Inui M. 2015. Glucose consumption rate critically depends on redox state in Corynebacterium glutamicum under oxygen deprivation. Appl Microbiol Biotechnol 99:5573-5582.

41. Juturu V, Wu JC. 2016. Microbial production of lactic acid: the latest development. Crit Rev Biotechnol 36:967-977.

42. Liu J, Kandasamy V, Würtz A, Jensen PR, Solem C. 2016. Stimulation of acetoin production in metabolically engineered Lactococcus lactis by increasing ATP demand. Appl Microbiol Biotechnol 100:9509-17.

43. Wang Z, Liu J, Chen L, Zeng AP, Solem C, Jensen PR. 2018. Alterations in the transcription factors 
GntR1 and RamA enhance the growth and central metabolism of Corynebacterium glutamicum. Metab Eng 48:1-12.

44. Sambrook J, Fritsch EF, Maniatis T. 1989. Molecular Cloning: A Laboratory Manual. Cold Spring Harbor laboratory press.

45. Eggeling L, Bott M. 2005. Handbook of Corynebacterium glutamicum. Taylor \& Francis.

46. Schäfer A, Tauch A, Jäger W, Kalinowski J, Thierbach G, Pühler A. 1994. Small mobilizable multipurpose cloning vectors derived from the Escherichia coli plasmids pK18 and pK19: selection of defined deletions in the chromosome of Corynebacterium glutamicum. Gene 145:69-73.

47. Kirchner O, Tauch A. 2003. Tools for genetic engineering in the amino acid-producing bacterium Corynebacterium glutamicum. J Biotechnol 104:287-299.

48. Liu J, Dantoft SH, Würtz A, Jensen PR, Solem C. 2016. A novel cell factory for efficient production of ethanol from dairy waste. Biotechnol Biofuels 9:33.

49. Huang DW, Sherman BT, Lempicki RA. 2008. Bioinformatics enrichment tools: paths toward the comprehensive functional analysis of large gene lists. Nucleic Acids Res 37:1-13.

50. Huang DW, Sherman BT, Lempicki RA. 2009. Systematic and integrative analysis of large gene lists using DAVID bioinformatics resources. Nat Protoc 4:44-57.

51. Chen J, Shen J, Solem C, Jensen PR. 2013. Oxidative stress at high temperatures in Lactococcus lactis due to an insufficient supply of riboflavin. Appl Environ Microbiol 79:6140-6147.

52. Kurosawa K, Wewetzer SJ, Sinskey AJ. 2013. Engineering xylose metabolism in triacylglycerolproducing Rhodococcus opacus for lignocellulosic fuel production. Biotechnol Biofuels 6:134. 
Table 1. Strains and plasmids used in the study.

\begin{tabular}{|c|c|c|}
\hline Strain/Plasmid & Description/Function & Reference \\
\hline \multicolumn{3}{|l|}{ Strains } \\
\hline JS112 & C. glutamicun::lacSZ::galMKTE, $\Delta l d h, \Delta p p c$ & (15) \\
\hline JS119 & JS112, $\Delta m d h$ & This study \\
\hline JS122 & JS112 harboring pJS115 (ethanol-producing plasmid) & (15) \\
\hline JS124 & JS119 harboring pJS115 & This study \\
\hline JS125 & $\begin{array}{l}\text { C. glutamicun } \Delta l d h, \Delta p p c, \Delta m d h \text {, replacement of the lpd gene } \\
\text { with E.coli's }\end{array}$ & This study \\
\hline JS125A & Isolation from evolved JS125 & This study \\
\hline JS132 & JS125A, $\Delta z w f$ & This study \\
\hline JS133 & JS125A harboring pJS115 & This study \\
\hline JS134 & JS132 harboring pJS115 & This study \\
\hline JS137 & JS112 harboring pJS136 (D-lactate-producing plasmid) & This study \\
\hline JS138 & JS132 harboring pJS136 & This study \\
\hline JM140 & JS112 harboring pJM140 (Alanine-producing plasmid) & This study \\
\hline JM141 & JS132 harboring pJM140 & This study \\
\hline \multicolumn{3}{|l|}{ Plasmids } \\
\hline pAL347 & E. coli-C. glutamicum expression shutter vector, $\operatorname{Spec}^{\mathrm{R}}$ & (52) \\
\hline pEC-XK99E & E. coli-C. glutamicum expression shutter vector, & (47) \\
\hline pK18mobsacB & $\begin{array}{l}\text { used for the construction of gene insertion and deletion } \\
\text { C.glutamicum mutants, } \operatorname{Kan}^{\mathrm{R}}\end{array}$ & (46) \\
\hline pJS115 & 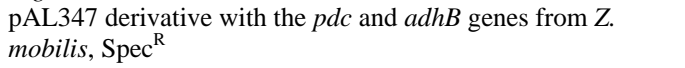 & This study \\
\hline pJS136 & $\begin{array}{l}\text { pEC-XK99E derivative with the } D \text {-ldh gene from } \\
\text { Lactobacillus delbrueckii }\end{array}$ & This study \\
\hline pJM140 & $\begin{array}{l}\text { pEC-XK99E derivative with the alaDH gene from } \\
\text { Lysinibacillus sphaericus }\end{array}$ & This study \\
\hline pK18-mdh & Deletion of $m d h$ gene in $C$. glutamicum & This study \\
\hline pK18-Ipd & Replacement of $l p d$ gene with $E$. coli 's & This study \\
\hline pK18-zwf & Deletion of $z w f$ gene in C. glutamicum & This study \\
\hline
\end{tabular}




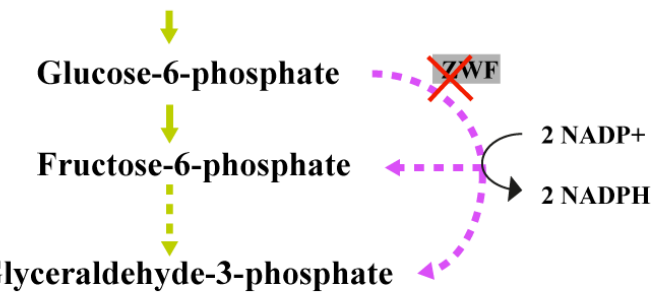

PEP

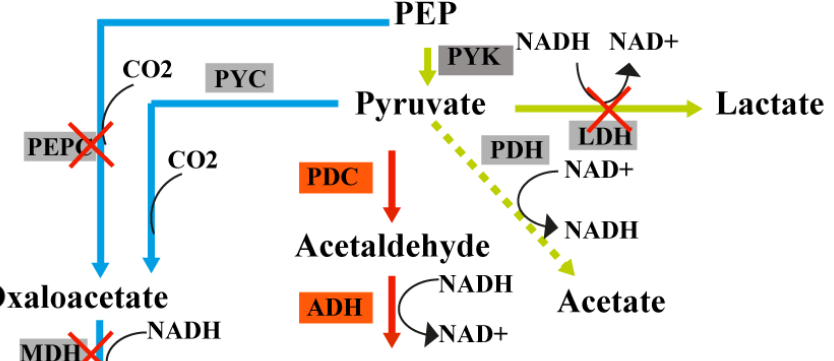

Ethanol

$$
\text { Malate }
$$

FUM

Fumarate

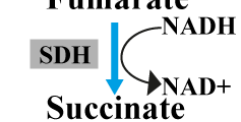

Figure 1. Schematic overview of sugar metabolism in C. glutamicum under anoxic conditions. The grey boxes indicate the relevant enzymes. LDH, lactate dehydrogenase ( $l d h A$ gene); PEPC, phosphoenolpyruvate carboxylase ( $p p c$ gene); PYC, pyruvate carboxylase ( $p y c$ gene); $\mathrm{MDH}$, malate dehydrogenase ( $m d h$ gene); FUM, fumarase; SDH, succinate dehydrogenase; PDH, pyruvate carboxylase; G6PDH, glucose-6-phosphate dehydrogenase (zwf gene). The Z. mobilis PDC (pyruvate decarboxylase ( $p d c$ gene)) and ADH (alcohol dehydrogenase (adhB gene)) enzymes, which expressed in C. glutamicum in this study, are shown in the red boxes. Red Xes indicate the deletion of the relevant genes. 
A

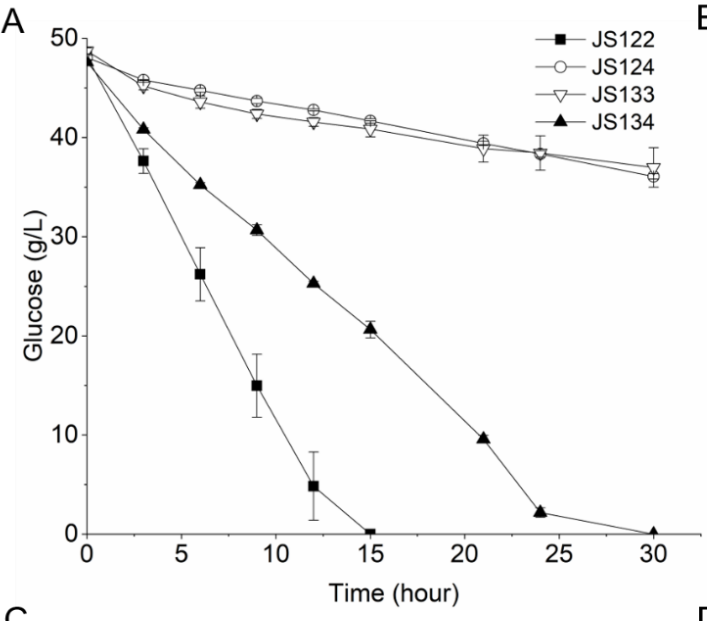

C

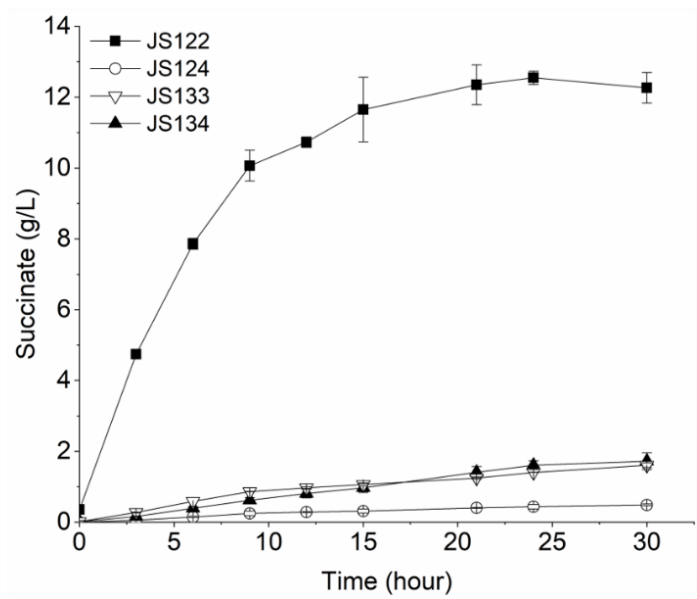

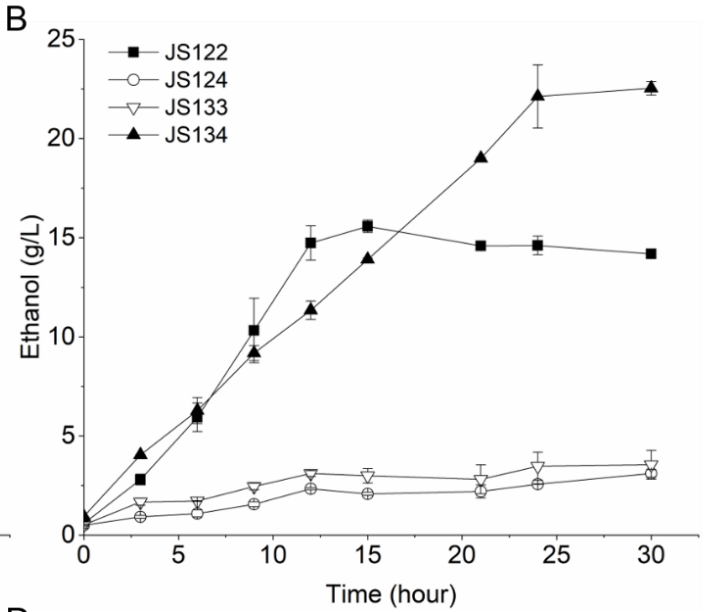

D

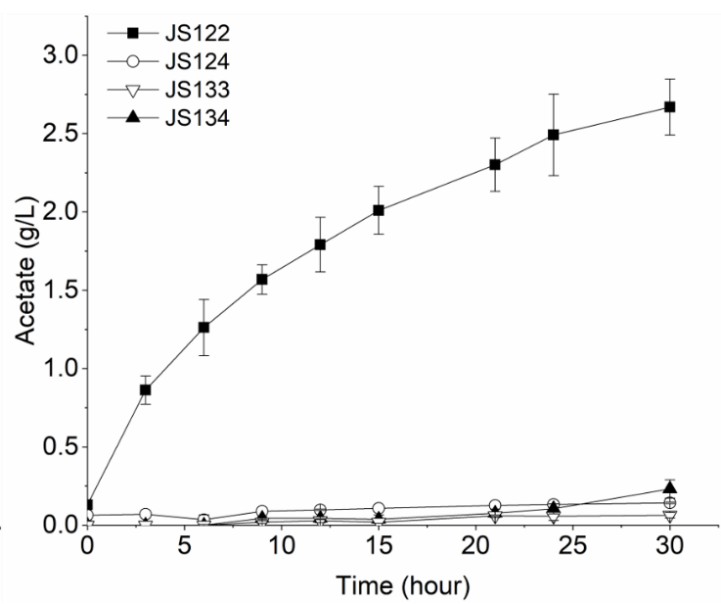


646
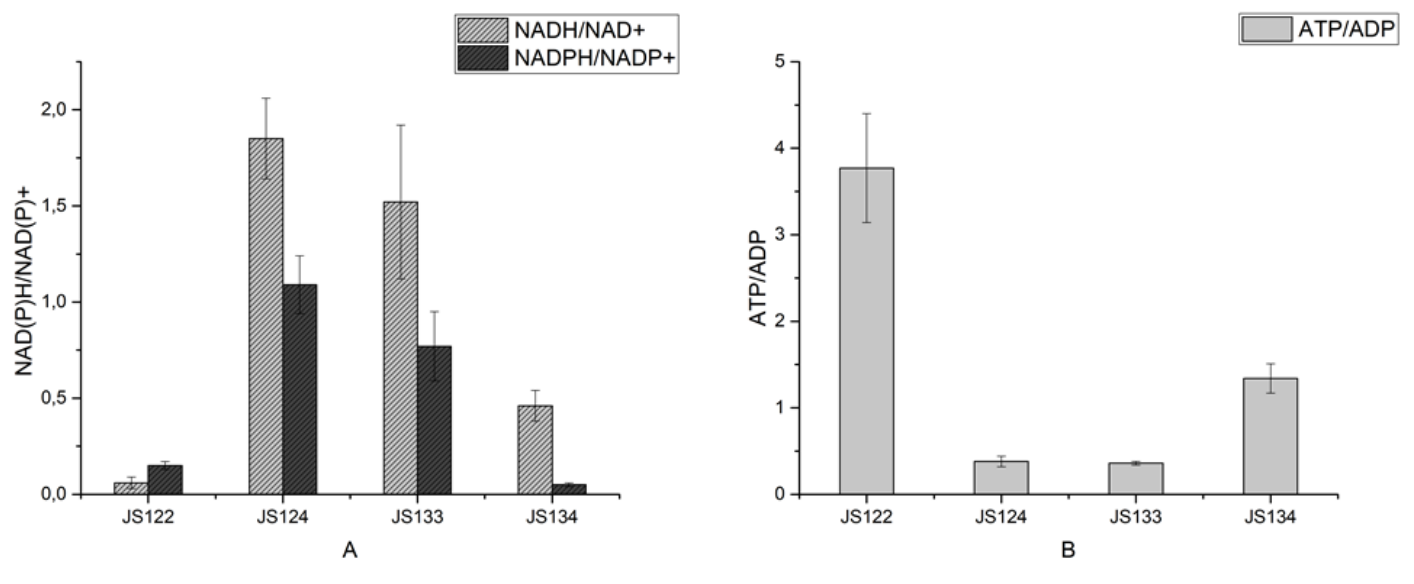

648 Figure 3. Measurement of NADH/NAD ${ }^{+}, \mathrm{NADPH} \mathrm{NADP}^{+}$and ATP/ADP in different strains under

649 anoxic conditions. Two biologically independent experiments were performed to calculate the 650 standard deviation.

651

652

653

654

655

656

657

658

659 
A

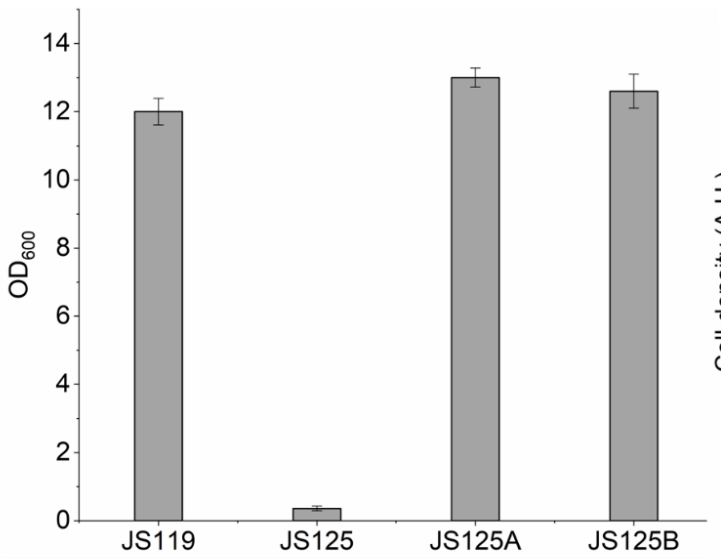

B

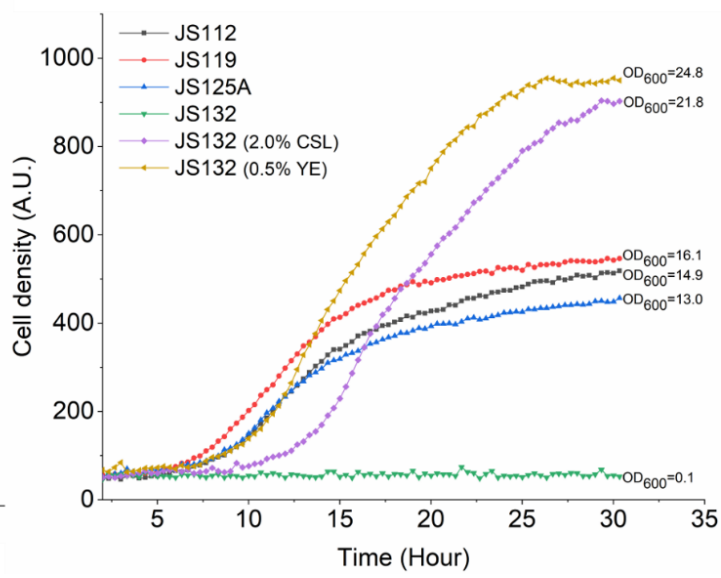

661 Figure 4. Characterization of strain growth. A. Comparison of the final cell density $\left(\mathrm{OD}_{600}\right)$ after 40

$662 \mathrm{~h}$ aerobic growth in mimimal medium containing glucose, the growth experiments were carried out

in $100 \mathrm{~mL}$ shake flask with $20 \mathrm{~mL}$ medium. The standard deviations were calculated from three 


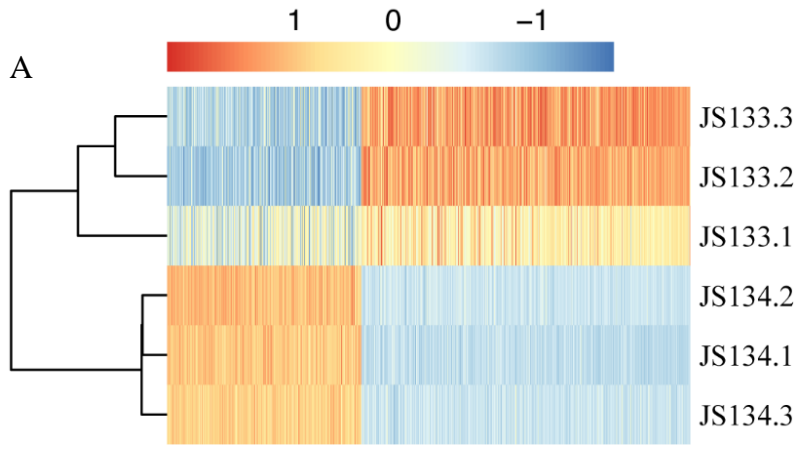

B

Percentage of down-regulated genes

Percentage of up-regulated genes

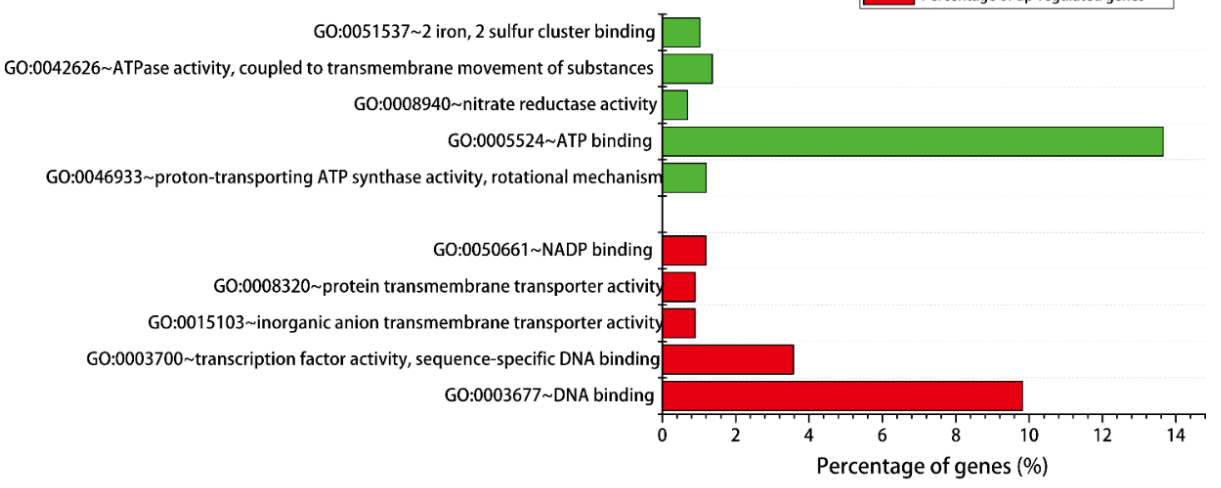

676

677 Figure 5. Transcriptomics for JS134 and JS133 (three independent replicates for each). A. The

678 heatmap for the differentially expressed genes was made using pheatmap in R. B. Enriched GO

679 terms for the up-regulated and down-regulated gene in JS134 when using JS133 as the reference. 


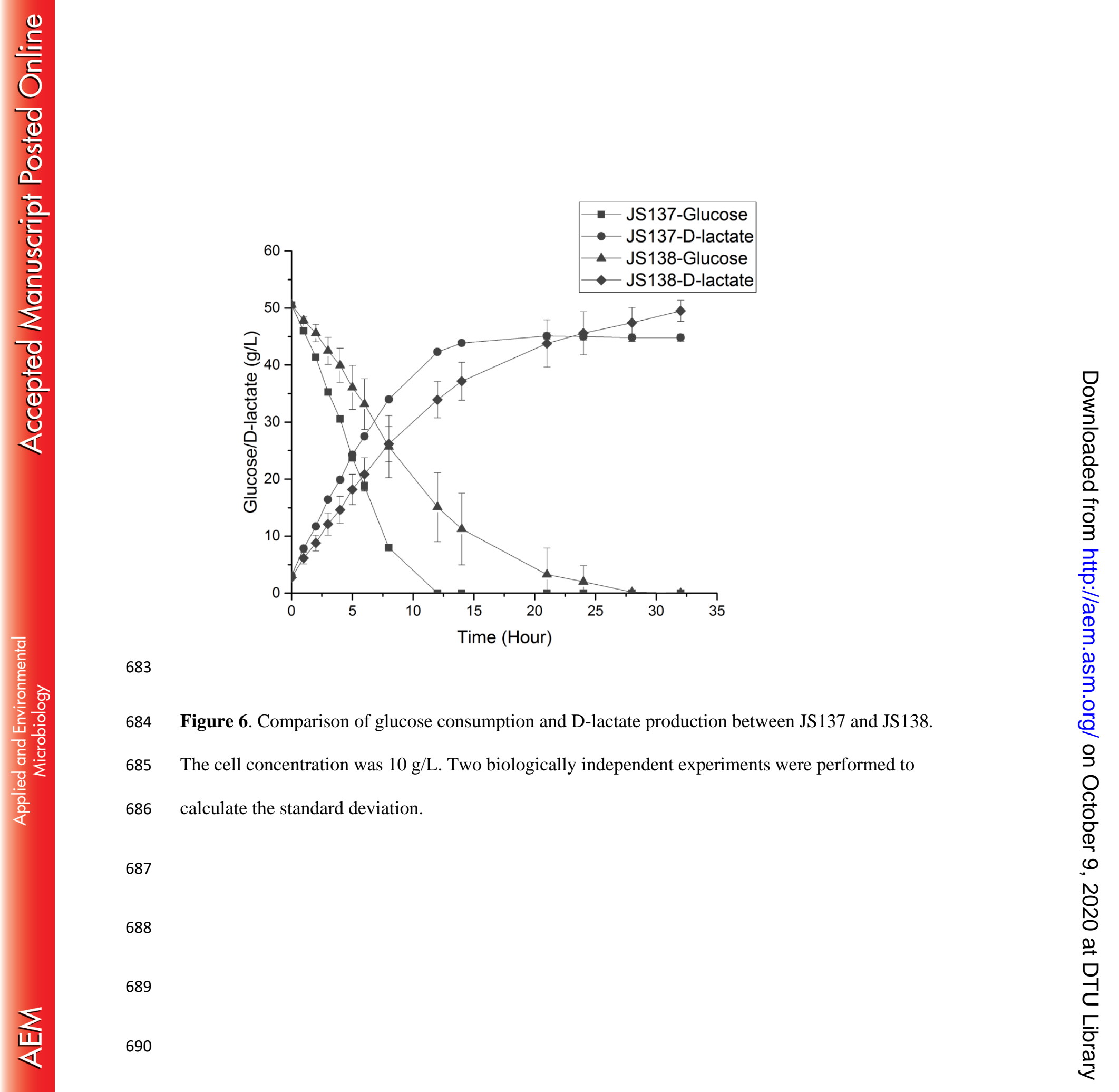

691 
A
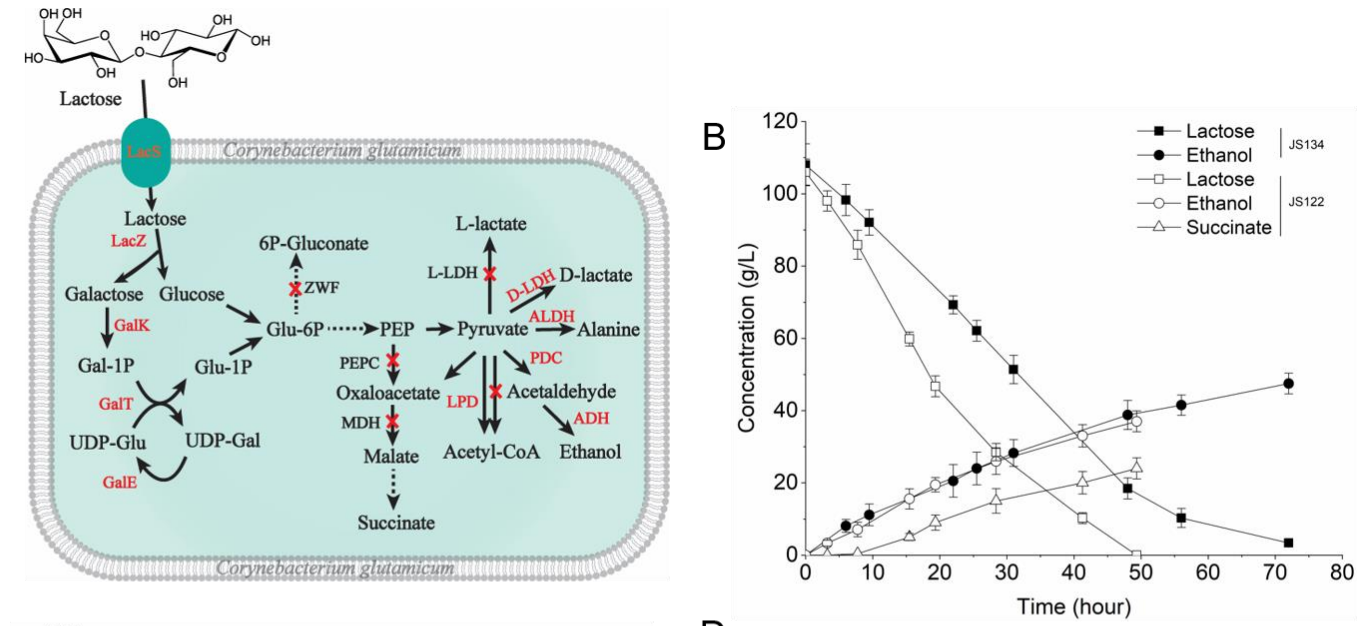

C

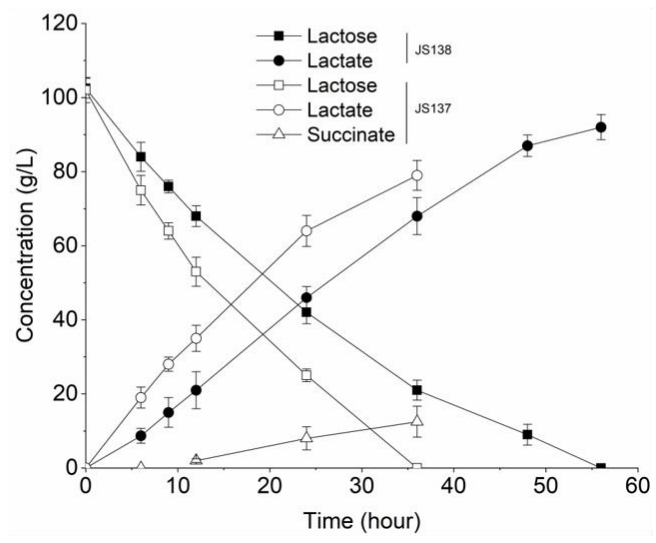

